\title{
Camilo Castelo Branco e Honoré de Balzac: de influências culturais e poetas fortes
}

\author{
Ana Luísa Patrício Campos de Oliveira ${ }^{1}$
}

RESUMO: Com vistas a um estudo literário comparativista despojado de noções de fonte, influência e dependência cultural, objetivamos aqui mostrar como os autores oitocentistas Honoré de Balzac e Camilo Castelo Branco veiculam suas respectivas críticas sociais ao materialismo preponderante no século XIX de modos distintos e inovadores. Para tanto, analisaremos brevemente dois romances, o balzaquiano Eugénie Grandet e o camiliano Onde está a felicidade?

ABSTRACT: For a comparative literary study released from notions of source, influence and cultural dependence, we aim to show how the nineteenth century authors Honoré de Balzac and Camilo Castelo Branco convey their social criticism of the materialism predominant in the nineteenth century by different and innovative modes. Therefore, we will briefly analyze two novels, Balzac's Eugénie Grandet and Camilo's Onde está a felicidade?

PALAVRAS-CHAVE: Honoré de Balzac; Camilo Castelo Branco; Influência cultural; Critica social.

KEYWORDS: Honoré de Balzac; Camilo Castelo Branco; Cultural influence; Social criticism.

Como sabemos, a Literatura Comparada surge em meados do século XIX na França e seu aparecimento é, em muito, decorrente do “pensamento cosmopolita que caracterizou [...] [esse período], época em que comparar estruturas ou fenômenos análogos, com a finalidade de extrair leis gerais, foi dominante nas ciências naturais" (CARVALHAL, 2006, p. 8). De fato, em sua origem, a Literatura Comparada intencionava estudar as questões relacionadas à fonte e à influência ${ }^{2}$, procurando, dessa forma, "estabelecer filiações e [...] determinar

\footnotetext{
${ }^{1}$ Doutoranda USP. Contato: ana.luisa.oliveira@usp.br

2 Para uma compreensão mais aprofundada do tema, verificar a obra de Pierre Brunel Que é literatura comparada.
} 
imitações ou empréstimos" (CARVALHAL, p. 13) realizados entre autores pertencentes a literaturas nacionais distintas.

Assim posto, encontramos a Literatura Comparada desse período permeada pelo conceito de nacionalidade e pelas noções de fonte e influência, fatores estes que conduzem os estudos comparativistas à veiculação da existência de uma dependência cultural por parte das literaturas dos países periféricos. Isto porque, como afirma a estudiosa Tania Carvalhal,

Ao empreenderem a [...] [busca de analogias], os comparativistas clássicos tinham uma ideia fixa: identificar a semelhança ou identidade entre as obras aproximadas. [...] Mas havia nesse procedimento uma outra intenção: estabelecida a analogia, instalava-se o débito. E a relação se convertia num saldo de créditos e débitos.

É possivel ainda descobrir, subjacente a esses procedimentos e a essas conclusões, outra intenção mais oculta: a demarcação da dependência cultural. Reconhecida a semelhança, contraída a divida, chegava-se, com naturalidade, a uma conclusão: a dominação cultural de um país (de uma cultura) sobre outro (ou outra). [...]

Vista assim, a literatura comparada tinha uma falsa feição de internacionalismo e de espírito de abertura e aceitação. Investigar uma influência, cavoucar as fontes, significava descobrir que uma determinada cultura era superior a outra, portanto, dominante. (CARVALHAL, p. 75-76)

Em seguida, a autora assegura que a solução possivel para que a Literatura Comparada se despoje dessa perspectiva de dominação cultural é o estudo das diferenças, em substituição do das analogias, uma vez que este recurso possibilita que mais facilmente se afirme a qualidade literária intrínseca a cada literatura nacional: "a investigação de um mesmo problema em diferentes contextos literários permite que se ampliem os horizontes do conhecimento estético ao mesmo tempo em que, pela análise contrastiva, favorece a visão crítica das literaturas nacionais" (CARVALHAL, p. 86).

Em concordância a esse pensamento proposto por Carvalhal, o pesquisador Benjamin Abdala Junior propõe, tendo em mente a comunidade literária dos países de língua oficial portuguesa, 
um “comparatismo da solidariedade” (ABDALA JR., 2003, p. 67), isto é, um procedimento de comparação literária que leve em conta não mais uma busca por imitações, mas sim "o que existe de próprio e de comum" (ABDALA JR., p. 67) nas culturas analisadas. Para tanto, o autor aponta a necessidade de um descentramento de perspectivas, um olhar analítico-comparativo anti-eurocêntrico que observe as culturas a partir de "um ponto de vista próprio". (ABDALA JR., p. 67)

Em suma, temos aqui proposta uma linha de estudo que visa à comparação literária com fins a sublinhar as particularidades de cada cultura sem noção de valoração ${ }^{3}$. Vale salientar que tal proposta possui um viés marcadamente multicultural, uma vez que tem como intuito promover "o reconhecimento e visibilidade das culturas marginalizadas [...]" (SANTOS, 2003, p. 29).

De fato, essa nova perspectiva comparativista que se apresenta, um olhar descentrado e despojado de noções de fonte e influência que visam a atribuição de valores, noções estas que tendem a rebaixar, sem maiores mesuras, as literaturas que sofreram influências de outras culturas, torna-se ainda mais necessária quando levamos em conta as considerações do estudioso Harold Bloom: "a influência poética não acarreta, por definição, a diminuição da originalidade; com igual frequência, é capaz de tornar um poeta mais original, o que não quer dizer necessariamente melhor" (BLOOM, 1991, p. 35-36). Trata-se dos denominados "poetas fortes" ou "autênticos" (BLOOM, p. 62), escritores que demonstram como a herança cultural pode ser utilizada em favor da elaboração de um legado artístico inovador, que promove uma "desleitura" (BLOOM, p. 62) do modelo precedente, a partir de "um ato de correção criativa” (BLOOM, p. 62).

\footnotetext{
3 Vale ressaltar que essa perspectiva comparativista proposta por Carvalhal e Abdala Jr. encontra-se em consonância com a linha de pensamento desenvolvida pelos estudiosos culturalistas da segunda metade do século XX, mais especificamente os pesquisadores do Centre for Contemporary Cultural Studies (CCCS). Em sintese, trata-se de um grupo de pesquisadores que buscou estudar e legitimar objetos culturais até então desprezados academicamente, ou seja, produtos e práticas advindos das culturas populares. (Cf. MATELLART, 2004).
} 
Com efeito, essa ponderação feita por Bloom finda por nos encaminhar à hipótese de estudo que procuraremos desenvolver a seguir, uma linha de pesquisa que intenciona afirmar a inexistência da chamada "dependência cultural" por parte das literaturas ditas marginais e assegurar a existência de, principalmente durante o século XIX, periodo que aqui nos interessa focar, um fluxo cultural de influências literárias determinado por questões mercadológicas. Entretanto, antes de nos aprofundarmos neste tocante, vejamos como se constitui, geograficamente, este fluxo.

Segundo estudiosos do período oitocentista, trata-se de um trânsito cultural estabelecido de forma unidirecional: os produtos culturais surgidos em Inglaterra e França no século XIX tornavam-se modelares para países periféricos, como Portugal, Espanha, Japão, Índia etc. A respeito deste fluxo cultural - centro (anglo-francês) / periferia - determinado mercadologicamente, Franco Moretti, autor que acredita na existência da "dependência cultural" que objetivamos mais adiante refutar, afirma:

Problemas, contradições, paradoxos, fracassos, defeitos, terreno inadequado para o florescimento do romance, mal resolvidos... Mercados e formas, diz o título dessa seção; bem, é desse modo que o mercado influencia as questões de forma. No caso das literaturas menos poderosas (o que significa quase todas as literaturas, dentro e fora da Europa) -, no caso dessas culturas menos poderosas, o sucesso do modelo anglo-francês no mercado internacional implica uma série infinita de formações acomodáticas; e formações frágeis, instáveis: programas impossiveis, fracassos e tudo o mais. É ainda o "desenvolvimento no subdesenvolvimento" dentro do campo literário: onde a dependência aparece - infelizmente - como a força decisiva da vida cultural. (MORETTI, 2003, p. 205)

Nesse sentido, estamos diante de um percurso cultural que marca um fluxo unilateral, na medida em que escritores ingleses e franceses tornam-se referência para autores ditos periféricos, sendo seu inverso inexistente, consoante o crítico. Em verdade, uma forma de identificarmos a presença deste fluxo cultural anglo-francês que se espraia para todas as demais culturas dentro e fora da Europa é o 
modo como a crítica literária aponta a rede de influências sofridas por autores oitocentistas.

A título de exemplificação, peguemos os autores sobre os quais mais à frente nos deteremos. Se para o autor português Camilo Castelo Branco é absolutamente plausível e mencionado que suas influências são majoritariamente inglesas e francesas, devido ao fluxo cultural acima mencionado, para o escritor francês Honoré de Balzac torna-se impensável, pelo mesmo motivo, qualquer outra fonte que não seja igualmente francesa ou inglesa. Assim sendo, temos como precursores atribuídos a Balzac autores como Scott, Rabelais, Racine, Rousseau, Voltaire, Stendhal, entre tantos outros autores ditos centrais ${ }^{4}$. Como vemos, nenhum autor periférico é mencionado como possivel precursor da literatura balzaquiana: o centro cultural do século XIX parece dialogar somente com seus pares. E para o escritor português Camilo Castelo Branco, as fontes apontadas pela crítica são também essencialmente "centrais": Scott, Dumas, Rousseau, Voltaire, Zola e o próprio Balzac ${ }^{5}$. Temos, portanto, na obra camiliana, uma das tantas literaturas representantes das culturas oitocentistas denominadas marginais, uma nitida ascendência francesa e inglesa, assim como as exigências mercadológicas do período o impunham.

Nesse sentido, podemos afirmar, a partir do exemplo acima mencionado, que o percurso cultural existente no século XIX dá-se de maneira unidirecional a partir de um centro - anglo-francês - que se irradia para toda uma imensa periferia, formada pelos demais países do globo, trânsito cultural este de cunho mercadológico.

Assim posto, uma vez definido como se dá, em termos geográficos, o que aqui denominamos fluxo cultural oitocentista, torna-se oportuno demonstrarmos, por meio de uma análise comparativa, o motivo pelo qual cremos tratar-se de um fluxo e não de uma dominação cultural exercida pelos países centrais. Para tanto, tomaremos como base dois

\footnotetext{
4 A respeito das influências literárias balzaquianas, verificar a obra de Georg Lukács, Balzac et le réalisme français.

5 No que concerne às influências literárias camilianas, observar a obra de Jacinto do Prado Coelho, Introdução ao estudo da novela camiliana.
} 
romances, o balzaquiano Eugénie Grandet (1833) e o camiliano Onde está a felicidade? (1856), procurando demonstrar, a partir de um exame despojado de estereótipos estabelecidos a priori, como ambas as literaturas destes romancistas lidam com o tema da crítica social em seus romances, temática esta explorada primeiramente pelo escritor francês ${ }^{6}$, mas que não deixou de ser abordada de forma criativa, inovadora e diferenciada por Camilo Castelo Branco, assim como conceitua ser possível Harold Bloom. Vale ressaltar que, dada a brevidade deste estudo, optamos aqui por focar nas personagens femininas centrais dos romances acima mencionados.

Comecemos pela obra partícipe da Comédie humaine. Eugénie Grandet é um romance que gravita em torno de, fundamentalmente, três personagens: Félix Grandet, um avarento típico, sua ingênua filha, Eugénie Grandet, e seu ambicioso sobrinho, o jovem Charles Grandet. No que concerne à personagem Eugénie, podemos observar que ela é sempre descrita pelo narrador como alguém que é puro altruísmo, ingenuidade, bondade e resignação: tudo aquilo que o pai avarento não pratica, exacerba-se e norteia a trajetória da jovem filha.

Com efeito, durante todo o desenrolar da narrativa, o enunciador adota uma postura de observação laudatória acerca de Eugénie: as suas atitudes de abnegação e resignação nunca são recriminadas, elas são, muito antes, descritas e compreendidas pelo enunciador balzaquiano. Nos momentos mais importantes da intriga - quando Eugénie entrega sua pequena fortuna a Charles, aceita o castigo imposto pelo pai, cede ao pedido paterno de abrir mão da herança materna, paga a divida de Charles, aquela que ele herdara do pai, Guillaume Grandet, mesmo sabendo que ele pretende se casar com uma nobre ao invés de cumprir sua promessa de amor feita na

${ }^{6}$ Acerca do intuito camiliano de reelaborar ficcionalmente a crítica social composta por Balzac, afirma Aníbal Pinto de Castro: “O problema consistia, essencialmente, em conciliar o gosto 'poético' dos leitores, sempre interessados numa ficção que lhes proporcionasse uma visão da vida mais atraente do que a própria vida, capaz de lhes criar uma evasão fácil em mundos ideais, com a preocupação, tão característica do romance de atualidade, segundo o modelo da Comédie humaine de Balzac, isto é, pintar os costumes de uma sociedade que, no plano do real, se movia por forças que eram a negação daqueles ideais que os leitores procuravam imaginativamente no mundo da ficção (CASTRO, 1991, p. 53, grifo do autor). 
juventude, e casa-se, sem amor, com o senhor de Bonfons - o narrador nunca a critica nem a repreende por se submeter a circunstâncias adversas, mantendo essa postura até o final dos sucessos:

[...] Deus lançou, portanto, montes de ouro à sua prisioneira, para quem o ouro era indiferente e que só aspirava ao céu, que vivia piedosa e boa, em santos pensamentos, e que incessantemente socorria em segredo os necessitados.

A sra. de Bonfons enviuvou aos trinta e três anos, com oitocentas mil libras de renda, bela ainda, mas com a beleza de uma mulher de quase quarenta anos. Seu rosto é pálido, repousado, calmo. [...] Possui todas as nobrezas da dor, a santidade da pessoa que não enxovalhou a alma em contato com o mundo, mas, também a dureza da solteirona e os hábitos mesquinhos da vida limitada da provincia. [...]

Tal é a história dessa mulher, alheia ao mundo no meio do mundo; e que, feita para ser uma excelente esposa e mãe, não tem marido, nem filhos, nem família. (DE BALZAC, 1947, p. 369 370)

Em suma, o narrador balzaquiano adota uma postura de complacente observação diante de sua heroína, uma personagem que, como ele mesmo enfatiza, viveu em um mundo corrompido pelas relações capitalistas sem ceder às suas falácias e, talvez por não ter cedido em momento algum, termina o romance sem encontrar a felicidade.

Já na produção camiliana, encontramos uma postura narratológica muito diferente: ao invés de uma observação sóbria e favorável às personagens, um enunciador que busca os pontos positivos dos entes ficcionais para evidenciá-los, como a bondade de cariz antimaterialista de Eugénie Grandet, temos um narrador que observa os movimentos sociais a partir de uma ótica acentuadamente crítica. Vejamos como o narrador camiliano exerce de modo inovador sua crítica social por meio da personagem Augusta.

Onde está a felicidade? é uma obra ambientada nos idos de 1840 e 50 e conta, em resumo, a história dos amores contrariados do rico Guilherme do Amaral, mancebo da provincia da Beira Alta, e da jovem Augusta, uma costureira de suspensórios da cidade do Porto. No que diz respeito a Augusta, durante todo o romance percebemos que ela 
adota uma postura em nada similar a de uma heroina abnegada ou resignada: algumas atitudes suas demonstram um caráter voluntarioso e cheio de brios, caráter este a todo o momento enfatizado pela voz enunciativa.

À guisa de exemplo, ressaltemos alguns episódios da narrativa nos quais atitudes nada submissas ou resignadas são postas em prática: ela se torna amante de Guilherme do Amaral à revelia dos costumes da época, mas nem por isso aceita passivamente ou envergonhada o abandono de Guilherme do Amaral e, contra a vontade dele, deixa o Candal e a vida luxuosa que lhe é ofertada e retorna à cidade do Porto. Também, nas últimas páginas do romance, ela, ao encontrar uma fortuna escondida, esquece-se rapidamente do filho que nasceu morto, aceita se casar com Francisco, seu primo, e tornar-se a rica, e, portanto, honrada, baronesa de Amares, reabilitando-se, com ares de vingança, perante a argentária sociedade portuguesa oitocentista sem a ajuda do dinheiro do antigo amante. A esse respeito, temos o diálogo final entre o jornalista e Guilherme, no qual se afirma que Augusta somente conseguiu se ver livre da influência de Amaral, justamente, por ter encontrado e usufruído de uma avultada soma:

$-[\ldots]$ Sabes o que é a felicidade em Augusta? é o esquecimento. Sabes onde se encontra o esquecimento? A mitologia diz que é no Letes; eu, que não sou pagão, digo que é nas mil diversões que oferece o dinheiro. Em suma, queres saber onde está a felicidade?

-Se quero!!...

-Está de baixo de uma tábua, onde se encontram cento e cinqüenta contos de réis. E... adeus. Vou ao baile.

(CASTELO BRANCO, 1970, p. 374, grifo do autor).

Nesse sentido, podemos vislumbrar que Onde está a felicidade? é um romance no qual o dinheiro é o elemento sine qua non, e, diferentemente do que nos foi apresentado em Eugénie Grandet, a protagonista consegue encontrar a felicidade por meio dele, até mesmo porque, em contraponto a Eugénie Grandet, Augusta é uma mulher do mundo em meio ao mundo, ou seja, ela se permite a adaptação às contingências mundanas ao invés de viver eternamente em busca de 
um amor ideal. De fato, essa é a opinião veiculada pelo narrador no transcorrer dos sucessos: Augusta é uma personagem com vícios e virtudes, uma mulher pobre, que "precis[a] de dinheiro" (CASTELO BRANCO, 1970, p. 139) para sobreviver e sempre se orgulha de sua honra imaculada, mas que, contrariando seus princípios, não resiste à tentação de se tornar amante de um rico sedutor. Vejamos algumas passagens em que esse pensamento é expresso pelo enunciador. No momento em que Guilherme do Amaral propõe o concubinato seguido de casamento, algo que não se concretiza, a Augusta, o narrador comenta: "Mulher como todas, Augusta queria suspeitar as intenções de Guilherme [...]" (CASTELO BRANCO, 1970, p. 138). Já no episódio da saída de Augusta da casa do Candal, a voz narrativa afirma, para que dúvidas não restem, que essa atitude foi motivada, consoante sua opinião, muito antes por "soberba" (CASTELO BRANCO, 1970, p. 297) do que por uma possivel "virtude" (CASTELO BRANCO, 1970, p. 296):

A renúncia das regalias do Candal, em quanto a mim, não era virtude, examinada em todas as suas faces. Se fosse, como dizem que são as virtudes cristãs, Augusta receberia todas as humilhações como espinhos de penitência. Estenderia a mão a receber esmolas de seu primo, e acolheria com agradecidas lágrimas todas as repreensões vindas dele ou da filha do barqueiro [a personagem Ana do Moiro]. [...]

Eis aqui o orgulho de mulher, que não pode cair nunca da nobre altivez, que, mesmo no infortúnio, a distingue. É esta soberba cunho da superioridade. [...] (CASTELO BRANCO, 1970, p. 296297)

Trata-se, pois, de um narrador que desconfia de prováveis atitudes abjuradas de suas personagens e faz questão de estudar seus entes ficcionais de forma problematizadora e marcadamente crítica. Estamos diante, portanto, de um enunciador que dá mostras de ser muito diferente do narrador balzaquiano, um observador brando, que ressalta as qualidades de suas personagens, sem duvidar delas.

Assim posto, notamos estar diante de obras que realizam formas diversas de crítica social: no romance balzaquiano uma crítica de viés acentuadamente brando e outra de cariz marcadamente mordaz na narrativa camiliana. Dessa forma, vemos concretizar-se na ficção 
camiliana a possibilidade enunciada por Harold Bloom: um escritor autêntico - Camilo Castelo Branco - recebe uma dada influência literária - o modelo balzaquiano de crítica social - e, a partir de "um ato de correção criativa" (BLOOM, 1991, p. 62), a reinventa e engendra uma obra de arte renovada que extrapola os limites anteriormente determinados. Assim sendo, temos em Camilo um exemplo de autor forte, que faz de sua principal influência literária não um elemento limitador, mas sim um ponto de partida de sua escrita romanesca.

Dessa forma, podemos constatar que a rede de influências anglofrancesas estabelecida no século XIX por razões mercadológicas pode ser definida em termos de fluxo cultural, uma vez que, como vimos presentificado nas obras balzaquiana e camiliana, a relação que se estabelece entre as literaturas centrais e as marginais não se dá por meio de dominação ou dependência, mas sim de interação, de revisitações a uma herança cultural que findam em renovados produtos culturais. Produtos estes que reforçam a idéia de cultura como algo em constante construção e reconstrução, como algo que representa a capacidade humana de, ininterruptamente, cultivar, reelaborar e inovar suas formas de expressão.

Por fim, ressaltamos a necessidade de se pensar, assim como propõe os estudiosos apontados no início do presente artigo, a análise comparativa das diversas literaturas existentes com vistas a um exame que priorize "o que existe de próprio e de comum" (ABDALA JR., 2003, p. 67) em cada literatura, visto que a adoção de tal perspectiva acaba por trazer à luz aspectos até o momento desconhecidos, como o fato de Camilo Castelo Branco poder não mais ser vislumbrado enquanto um autor marginal influenciado pelo mestre francês Honoré de Balzac, mas sim como um escritor forte, autêntico em sua proposta literária de crítica social. Como vemos, ainda há muito por fazer.

\section{Referências bibliográficas}


ABDALA JR., Benjamin. De vôos e ilhas. literatura e comunitarismos. São Paulo: Ateliê Editorial, 2003.

BLOOM, Harold. A angústia da influência: uma teoria da poesia. Rio de Janeiro: Imago, 1991.

BRUNEL, Pierre. Que é literatura comparada. São Paulo: Edusp, 1990.

CARVALHAL, Tania Franco. Literatura comparada. São Paulo: Ática, 2006.

CASTELO BRANCO, Camilo. Onde está a felicidade? Lisboa: Parceria A. M. Pereira, Lda, 1970.

CASTRO, Aníbal Pinto de. "Para uma teoria da ficção camiliana.". In: Arquivos doCentro Cultural Português, volume XXIX. Lisboa-Paris: Fundação Caluste Gulbenkian, 1991, p. 53 - 70.

COELHO, Jacinto do Prado. Introdução ao estudo da novela camiliana. Lisboa: Imprensa Nacional Casa da Moeda, 2001.

DE BALZAC, Honoré. "Eugénie Grandet" In: A comédia humana. Rio de Janeiro: Editora Globo, 1947.

LUKACS, Georg. Balzac et le réalisme français. Paris: La Découverte, 1999.

MATTELART, Armand. Introdução aos estudos culturais. São Paulo: Parábola

Editorial, 2004.

MORETTI, Franco. Atlas do romance europeu. São Paulo: Boitempo, 2003.

SANTOS, Boaventura de Sousa. Reconhecer para libertar: os caminhos do cosmopolitismo multicultural. Rio de Janeiro: Civilização Brasileira, 2003. 